\title{
INFLUENCIA DO ALINHAMENTO DE PLANTIO NA SEVERIDADE DA MANCHA-PRETA-DOS-CITROS, PRODUÇÃO E QUALIDADE DO SUCO ${ }^{1}$
}

\author{
ANDRÉ GUSTAVO DE ANDRADE², ADRIANO ALVES PIMENTA², ANTONIO DE GOES ${ }^{3}$
}

RESUMO - Os níveis de incidência e severidade de sintomas das doenças resultam da interação hospedeiro-patógeno-ambiente. Nesse contexto, a favorabilidade do ambiente, em particular, depende do nível de umidade, intensidade de radiação solar, luminosidade e molhamento foliar, dentre outros fatores. Por outro lado, a magnitude de expressão desses fatores é dependente do ciclo e porte das plantas, e possivelmente, também, do alinhamento de plantio. No presente estudo, foi avaliada a influência dos alinhamentos de plantio N-S, L-O, NE-SO e NO-SE no desempenho agronômico de plantas de laranjas 'Natal' e 'Valência', assim como na severidade de sintomas da mancha-preta-dos-citros (MPC), causada por Guignardia citricarpa. Para tal, foram selecionadas cinco propriedades distribuídas ao longo do cinturão citrícola paulista, de talhões semelhantes, a partir das quais foram coletadas amostras de 50 frutos, em dez plantas de mesma linha, da região central dos mesmos. Tais frutos foram levados para laboratórios e analisados quanto aos níveis de severidade de sintomas da MPC, produção e qualidade do suco. Constatouse que os frutos oriundos de pomares implantados no alinhamento N-S apresentavam menores níveis de severidade da doença, enquanto no alinhamento NE-SO, os mais elevados. Propriedades localizadas mais ao sul do Estado de São Paulo apresentaram menores níveis de doença, provavelmente em consequência da ocorrência recente da doença em tais áreas. Em relação à produção, os alinhamentos de plantio N-S e L-O proporcionaram maior número de frutos por planta, assim como quanto ao número de caixas por planta. Por outro lado, a menor produção foi verificada nos alinhamentos NO-SE. Em relação à qualidade do suco, não foi possível estabelecer um padrão definido em termos de ratio e ${ }^{\circ}$ Brix e os respectivos alinhamentos de plantio. Foi verificado que os valores de ratio foram menores nos frutos de pomares localizados mais ao sul do Estado, de maiores latitudes.

Termos para indexação: Citrus sinensis, Guignardia citricarpa, Phyllosticta citricarpa, produção, alinhamento de plantio.

\section{THE INFLUENCE OF CROP POSITIONING IN THE SEVERITY OF CITRUS BLACK SPOT, PRODUCTION AND JUICE QUALITY}

\begin{abstract}
The levels of incidence and severity of disease symptoms are a result of the host-pathogenenvironment integration. In this context, a favorable environment, in particular, depends on the level of humidity, intensity of solar radiation, luminosity and leaf wetness among other factors. On the other side, the magnitudes of these factors' expressions are dependent upon the plant's cycle and size, and possibly the crop alignment as well. In the present study, five properties distributed along the citrus agricultural belt of São Paulo were selected. With similar orchards and crop orientation going north-south, east-west, northeast-southwest and northwest-southeast, from which samples of 50 fruits from ten plants of the same central tree line were collected. These fruits were taken to a laboratory and analyzed for severity levels of citrus black spot (Guignardia citricarpa), production and juice quality. It was concluded that the fruits from crops in the east-west orientation presented lower symptom severity, while the north-south orientation, had the highest levels. Also, the farms located further south of São Paulo state, showed lower levels of the disease, probably due to the fact that such areas have shorter periods of disease occurrences. In relation to production, the north-south and east-west crop orientations produced the highest amount of boxes per plant, while the northwest-southeast and northeast-southwest had the lowest production levels. As for the juice quality, there was no concluding data to establish a defined standard in terms of ratio and ${ }^{\circ}$ Brix on the respective crop alignment. The relation between the latitude and ratio value was declared to be consistently lower in citrus orchards located further south in the state of Sao Paulo.
\end{abstract}

Index terms: Citrus sinensis, Guignardia citricarpa, Phyllosticta citricarpa, production, planting line direction.

\footnotetext{
${ }^{1}$ (Trabalho 288-08). Recebido em: 21-11-2008. Aceito para publicação em: 08-10-2009.

${ }^{2}$ Pós-Graduando de Agronomia (Produção Vegetal), Depto de Fitossanidade, FCAV/UNESP, Via de Acesso Prof. Paulo Donato Castellane s/n CEP 14884-900, Jaboticabal-SP. E-mail: aandrade@fcav.unesp.br. Bolsista CNPq. adriano.pimenta@br3.ind.br

${ }^{3}$ Prof. Assistente Doutor do Depto. de Fitossanidade, FCAV/UNESP, Via de Acesso Prof. Paulo Donato Castellane s/n, CEP 14884900, Jaboticabal-SP. E-mail: agoes@fcav.unesp.br Bolsista CNPq.
} 


\section{INTRODUÇÃO}

A produção de citros do ano agrícola de 2007/2008, no Estado de São Paulo e no Triângulo Mineiro, foi de 368 milhões de caixas de laranja de $40,8 \mathrm{~kg}$. Atualmente o Estado de São Paulo detém $97 \%$ das exportações brasileiras de suco de laranja, possuindo o maior parque citrícola do mundo, com cerca de 200 milhões de pés de laranja em 13.000 propriedades, em área de 691 mil hectares distribuídos ao longo de quase todo o Estado e Triângulo Mineiro (Secretaria de Estado de Agricultura, Pecuária e Abastecimento de São Paulo, 2008).

Em que pese a pujança socioeconômica do agronegócio citrícola, essa atividade apresenta vários problemas de ordem fitossanitária, com destaque para as doenças, incluindo-se a manchapreta-dos-citros (MPC), causada por Guignardia citricarpa.

A MPC deprecia os frutos, eleva os custos de produção e reduz a produtividade, dada a possibilidade de sua queda prematura. Trata-se de doença quarentenária $\mathrm{A} 1$ para os países da União Europeia e Estados Unidos da América, cujo nível de tolerância é zero. O custo de controle é elevado e, no caso da produção de frutos para exportação, é necessária a adoção de cuidados mais refinados, tanto na pré-colheita, como nas fases subsequentes, incluindo testes de indução de sintomas para certificação fitossanitária (Baldassari et al., 2007).

Os sintomas da MPC restringem-se praticamente à casca dos frutos, sem atingir o albedo, onde são descritos seis tipos de sintomas (Herbert, 1985; Baldassari et al., 2008). A expressão dos sintomas é favorecida por vários fatores, dos quais os mais importantes são a radiação solar intensa e as altas temperaturas por ocasião da maturação dos frutos, maior incidência de raios solares nos frutos expostos, estresse hídrico e debilidade das plantas (Kotzé, 1981). A relação entre severidade de sintomas e elevada luminosidade e temperatura foi, inclusive, demonstrada por Bodrick \& Rabie (1970).

É provável que o alinhamento de plantio influencie no nível de luminosidade, intensidade de radiação solar e molhamento foliar, dentre outras variáveis, com consequente efeito no desempenho agronômico das plantas, especialmente as arbustivas ou de grande porte. Na interação hospedeiropatógeno-ambiente, é provável, também, que o sentido do alinhamento exerça grande influência, podendo, assim, ter importância na intensidade de sintomas de doenças, especialmente aquelas causadas por fungos e bactérias.

Em termos agronômicos, especialmente na viticultura, o alinhamento de plantio tem grande influência nas características tecnológicas das frutas, com reflexos significativos nos teores de açúcar e sólidos solúveis (Ahmedullah, 1996). Segundo este autor, o efeito do alinhamento de plantio nesta cultura também se reflete na incidência de algumas doenças, uma vez que aqueles que proporcionam melhores condições de luminosidade e ventilação, reduzem o tempo de molhamento foliar, resultando em ambiente menos favorável aos patógenos. Ainda nessa cultura, embora o alinhamento de plantio seja predominante o do sentido $\mathrm{N}-\mathrm{S}$, em regiões mais quentes, adota-se o alinhamento NO-SE com o intuito de minimizar a exposição ao sol do período da tarde e maximizá-la no período da manhã.

No caso do agronegócio citrícola, não obstante a sua importância econômica, ampla distribuição geográfica e grandes áreas de cultivos, não há na literatura informações acerca da relação entre alinhamentos de plantios e aspectos fitossanitários da cultura. Entretanto, sabe-se que os fatores ambientais regulam os tipos de flores produzidas, sua distribuição na planta, a porcentagem de frutificação e, consequentemente, a produção (Davies \& Albrigo, 1994). No Hemisfério Norte, por exemplo, os frutos localizados no quadrante sul, na região apical da planta, são expostos a maior quantidade de energia radiante que, como consequência, apresenta maior concentração de sólidos solúveis em relação à área sombreada da região basal, do quadrante norte (Albrigo, 1993). No Brasil, Araújo et al. (1999) verificaram, no caso de laranjeira 'Pera', maior presença de flores no terço mediano da copa, no quadrante sudeste. Em termos de chumbinhos, a maior porcentagem foi verificada no terço basal no quadrante sudoeste.

A cultura dos citros, dada a continuidade espaço-temporal das áreas de cultivos e de órgãos suscetíveis, baixa variabilidade genética e o adensamento de plantio, a importância da melhoria das condições de luminosidade e ventilação, assim como da redução do tempo de molhamento foliar, não pode ser subestimada, dado o seu possível efeito no rendimento agronômico da cultura, assim como a predisposição às pragas e patógenos.

No contexto agronômico, a melhoria das condições de luminosidade e ventilação provavelmente se reflete nas características tecnológicas do suco, enquanto, em termos fitossanitários, sabe-se, por exemplo, que a doença das flores dos citros, designada Queda prematura dos frutos cítricos ou Podridão floral, causada por 
Colletotrichum acutatum, mostra-se muito mais grave quando da ocorrência simultânea de floradas associadas com chuvas e dias nublados, ou por longo período de molhamento foliar (Goes et al., 2008). O molhamento foliar, inclusive, além das chuvas, orvalhos e irrigação por aspersão, pode ser intensificado quando acompanhado de umidade relativa alta, temperatura amena, maior densidade de plantas e elevado sombreamento.

Quando da colheita dos frutos cítricos, toma-se como referência o índice de maturidade ou, simplesmente, ratio que é a razão entre as porcentagens de sólidos solúveis totais (SST) e de acidez total titulável (ATT) (Sinclair, 1984; Soule \& Grierson, 1986; Volpe et al., 2002). No Brasil, apesar de o consumo de suco de laranja concentrado congelado ser pequeno ( $5 \%$ do total produzido), verifica-se a preferência por sucos com ratio acima de 14. Todavia, o processamento industrial pode ser iniciado quando este se situa entre 12 - 13, embora a preferência o seja quando entre 15 e 18 (Marchi, 1993). Entretanto, especialmente nas variedades de laranjas-doces de maturação de meia-estação ou tardias, devido às condições ambientes, às vezes tal índice é alcançado mais tardiamente, o que se reflete de forma negativa nas estratégias de planejamento industrial e processamento das frutas.

Dado o exposto, e considerando a escassez ou ausência de informações quanto à influência do alinhamento de plantio dos pomares cítricos na manifestação das doenças e em variáveis agronômicas, o presente trabalho tem como objetivo: (i) estabelecer relação entre os alinhamentos de plantios dos pomares cítricos e incidência/ severidade de sintomas da mancha-preta-dos-citros, e (ii) determinar a sua influência na produtividade e características tecnológicas do suco.

\section{MATERIAL E MÉTODOS}

Foram selecionadas cinco propriedades citrícolas localizadas em diferentes regiões do Estado de São Paulo, cujos municípios, número de talhões, coordenadas geográficas, variedades e ano de plantio se encontram apresentados na Tabela 1 . Tais talhões, limítrofes entre si, localizavam-se em áreas de características topográficas e pedológicas semelhantes, cujas plantas foram enxertadas em limoeiro 'Cravo' (C. limonia Osbeck). O espaçamento de plantio de tais pomares era de $7,0 \mathrm{~m}$ x 3,5m, cujas plantas, dentro de cada propriedade, receberam os mesmos tratos culturais ao longo dos anos. Os alinhamentos de plantio selecionados foram: N-S, L-O, NO-SE e NE-SO. Para a identificação prévia dos alinhamentos de plantio, foram utilizadas fotos de satélite, com resolução espacial de $60 \mathrm{~cm}$, e verificação em campo através de caminhamento nas linhas de plantio, utilizando-se de GPS com precisão de $\pm 5 \mathrm{~m}$. O delineamento experimental utilizado foi o inteiramente casualizado, em arranjo fatorial 4 ou $8 \times 5$ (alinhamento ou face exposta x propriedade), com 10 e 20 repetições, respectivamente. No alinhamento de plantio, cada planta foi considerada uma repetição. Para o caso das faces, cada uma delas foi considerada como uma repetição.

Por ocasião da colheita dos frutos, em novembro de 2007, na área central do talhão, foram coletadas amostras de 50 frutos, em 10 plantas avaliadas consecutivamente, em cada face das mesmas, ao longo do seu eixo vertical. Após a colheita, procedeu-se à derriça e contagem dos frutos em cada uma das faces e, consequentemente, a produção unitária das plantas.

As amostras de frutos, então encaminhadas ao Laboratório de Fitopatologia do Departamento de Fitossanidade da UNESP, Câmpus de Jaboticabal, foram avaliadas quanto aos níveis de severidade de sintomas da mancha-preta-doscitros. Na avaliação da severidade, empregou-se escala de notas, considerando os diferentes tipos de sintomas (sintomas gerais) e os do tipo falsamelanose, conforme escala e procedimentos adotados, respectivamente, por Fagan \& Goes (1999) e Spósito et al. (2004). Após análise da severidade dos sintomas, os frutos foram levados para o Laboratório de Análise de Frutos da Citrovita Agroindustrial Ltda., em Catanduva-SP, onde foram determinados o seu peso médio, ${ }^{\circ}$ Brix e ratio. Os dados obtidos foram submetidos à análise de variância (Teste F) e teste de Tukey, ao nível de 5\% de probabilidade, para a comparação das médias.

\section{RESULTADOS E DISCUSSÃO}

$\mathrm{O}$ teste $\mathrm{F}$ foi significativo $(P<0,01)$ para todas as variáveis analisadas, assim como para as interações propriedades versus alinhamentos. Tal fato, contrariamente, não foi observado no tocante à interação alinhamentos versus faces (Tabela 2).

Em termos de severidade da doença, foi constatado efeito significativo do alinhamento de plantio, independentemente dos tipos de sintomas analisados (Tabela 3) Exceção faz-se apenas com relação à propriedade localizada em Santa Cruz do Rio Pardo (B), onde não foram constatadas diferenças significativas entre os alinhamentos, tanto para sintomas do tipo mancha- 
dura, como para o do tipo falsa-melanose. Em termos de sintomas do tipo mancha-dura, na propriedade localizada em Itapetininga (A), de forma semelhante ao observado em Santa Cruz do Rio Pardo, não foi observada relação entre os alinhamentos de plantios e a severidade da doença, embora, em termos numéricos, os menores valores tenham sido detectados no alinhamento NO-SE, e, contrariamente, os mais elevados em L-O. Tal fato, provavelmente, se deve ao baixo nível de doença em ambas as áreas, já que há registro de que a doença foi constatada apenas recentemente nas mesmas. No caso da propriedade localizada em Rio Claro (C), o nível mais baixo de severidade de sintomas da doença foi verificado para o alinhamento NO$\mathrm{SE}$, seguido de N-S, onde o mesmo foi também mais baixo. Nos demais alinhamentos, os níveis de severidade de sintomas foram significativamente mais elevados, não diferindo estatisticamente entre si, porém sendo diferentes dos alinhamentos anteriormente mencionados. Nas propriedades localizadas em Itirapina (D) e em Tambaú (E), os menores níveis de severidade foram observados no alinhamento $\mathrm{N}-\mathrm{S}$, que diferiu estatisticamente de todos os demais alinhamentos. Contrariamente, em termos de maior nível de severidade, houve uma tendência de que este se mostrasse mais acentuado em NE-SO. Nos demais alinhamentos, os níveis de severidade de sintomas foram intermediários e não diferiram estatisticamente entre si.

Em relação ao sintoma do tipo falsamelanose, no caso da propriedade $\mathrm{A}$, os níveis de sintomas foram muito baixos, não sendo possível a sua quantificação. No caso da propriedade B, os níveis de sintomas, embora igualmente baixos e quantificáveis, não foi constatada diferença estatística, independentemente do alinhamento avaliado. No caso da propriedade $\mathrm{C}$, o menor nível de severidade foi observado no alinhamento NO-SE, enquanto nos demais os níveis de severidade foram intermediários, sendo, às vezes, significativamente semelhantes ao anteriormente mencionado. Para o caso das propriedades $\mathrm{D}$ e E, os menores níveis de severidade foram observados para os alinhamentos $\mathrm{N}-\mathrm{S}$ e NO-SE, enquanto, contrariamente, os maiores o foram nos alinhamentos L-O e NE-SO. Em termos gerais, independentemente do tipo de sintoma avaliado, os menores níveis de severidade foram observados nos alinhamentos N-S e NO$\mathrm{SE}$, ao passo que os maiores o foram em NE-SO e L-O.

Em relação às faces, para o caso dos sintomas do tipo mancha-dura não foram encontradas diferenças significativas entre as mesmas, para as propriedades A e B. Entretanto, para as demais propriedades, foi constatada diferença estatisticamente significativa, onde, na maioria das vezes, as menores médias dos índices de severidade foram observadas para as faces $\mathrm{L}$ e $\mathrm{O}$, enquanto as maiores o foram para as faces $\mathrm{NO}$ e $\mathrm{SE}$, as quais corresponderam aos alinhamentos de plantios em $\mathrm{N}-\mathrm{S}$ e NE-SO, respectivamente. As faces L e O correspondem àquelas que recebem radiação solar de forma direta, o que provavelmente reflete em menor molhamento foliar. Os níveis de severidade de sintomas do tipo falsa-melanose foram muito baixos nas propriedades A e B, sendo quantificável apenas na segunda. Por outro lado, nas propriedades C, D e E, foram consistentemente mais expressivos, com menores índices nas faces L e O, acompanhadas, por vezes, das faces NE e SO. Os maiores níveis de severidade foram observados nas faces $\mathrm{N}$ e $\mathrm{S}$, e $\mathrm{NO}$ e $\mathrm{SE}$, as quais correspondem aos alinhamentos de plantios L-O e NE-SO, respectivamente.

Tomando-se como referência os dados de severidade de sintomas da MPC observados nas propriedades cujos índices de doenças foram mais elevados, as quais corresponderam a C, D e E, constata-se que, independentemente do tipo de sintoma, no alinhamento de plantio $\mathrm{N}-\mathrm{S}$, foi verificado o menor nível, enquanto os mais elevados o foram em NO-SE e L-O.

No alinhamento $\mathrm{N}-\mathrm{S}$, no período da manhã,os raios solares incidem diretamente na face $\mathrm{L}$ da planta, o que provavelmente redunda em menor período de molhamento foliar, parâmetro climático esse que tem expressivo efeito na germinação de esporos fúngicos, assim como nas demais etapas dos processos infecciosos. Por outro lado, no caso do alinhamento L-O, as faces $\mathrm{N}$ e $\mathrm{S}$ não contam com a incidência direta dos raios solares em razão do autossombreamento das plantas. Esse fato, provavelmente, contribui para um período de molhamento foliar de maior duração, cujos reflexos podem expressar-se em maior nível de severidade da doença. Tal efeito também ocorreu nos alinhamentos $\mathrm{NE}-\mathrm{SO}$ e NO-SE, com efeito nas faces NO/SE e NE/ $\mathrm{SO}$, respectivamente.

Em termos de região, para ambos os tipos de sintomas, houve diferença estatística, denotando sua influência nos níveis de severidade da doença. Tais níveis de severidade foram significativamente menores nas propriedades A e B, inclusive com diferenças entre ambas, e, de forma crescente, mais elevadas em C, D e E. Tais diferenças devem-se, provavelmente, ao tempo de início do estabelecimento do patógeno. Nas propriedades A e $\mathrm{B}$, situadas respectivamente nos municípios de 
Itapetininga e Santa Cruz do Rio Pardo, a ocorrência da doença é recente, estando por cerca de cinco anos. Nas demais, os registros são mais antigos e seguem as ordens: C, D e E. É provável, ainda, que tais diferenças estejam também associadas a aspectos bioecológicos locais e à influência climática. Embora as médias de temperaturas, mínima e máxima, e da precipitação pluviométrica, correspondentes ao período das safras de 2007 e 2008 não sejam tão díspares quando analisadas individualmente (dados não apresentados), quando vistas em conjunto as mesmas podem apresentar variações, cujo efeito pode manifestar-se com grande intensidade. Dessa forma, é possível que o efeito de tais variações seja muito significativo, já que a média de amplitude térmica e o tempo de molhamento foliar podem ser muito expressivos.

Quanto aos tipos de sintomas, há uma correspondência em termos de intensidade, independentemente da propriedade analisada, onde aquelas cujos frutos apresentavam sintomas do tipo mancha-dura em menor severidade, também o foram em relação aos do tipo falsa-melanose. O contrário também se aplica para situações cujas propriedades apresentaram níveis mais elevados de severidade.

Os valores do coeficiente de correlação determinados mediante os dados correspondentes aos índices de severidade para os sintomas dos tipos mancha-dura e falsa-melanose, tomados aos pares e individualmente para cada uma das propriedades, foram 0,14 para a propriedade $\mathrm{B}, 0,37$ para $\mathrm{C}$, $-0,08$ para $\mathrm{D}$ e 0,21 para E. Tais valores, embora baixos, foram significativos para as propriedades B e C $(P<0,01)$, assim como para a propriedade E $(P<0,05)$. Para o caso da propriedade $A$, não foi determinado o valor de tal coeficiente, já que a severidade de sintomas do tipo falsa-melanose deuse em nível muito baixo.

No caso das plantas cítricas, por tratar-se de planta perene e predominantemente autógama, é certo que a variabilidade genética é muito menor ou processa-se mais lentamente, quando comparada com aquela de plantas anuais alógamas. Neste contexto, dada a suscetibilidade das variedades de laranjas-doces e às características biológicas do fungo $G$. citricarpa, e também às condições propícias para o desenvolvimento da doença no Estado de São Paulo, presume-se que tal patógeno, uma vez presente, poderá apresentar taxas crescentes dos níveis de infecção, já que dispõe de duas formas efetivas para infecção: os conídios e os ascósporos. Tal ponto de vista mostra-se coerente com o exposto por Kotzé (1981), o qual ressalta que essa doença, uma vez presente em um determinado pomar, tende a apresentar taxas progressivas de infecção, como verificado nas condições da África do Sul. Além disso, os elevados níveis de severidade registrados nas propriedades $\mathrm{B}$ e $\mathrm{C}$, e particularmente em $\mathrm{D}$, onde a doença ocorre há mais tempo, também se constituem em alicerce para a hipótese apresentada.

Em relação ao número médio de frutos por árvore, no caso da propriedade $\mathrm{A}$, os valores mais elevados ocorreram nos alinhamentos de plantio L-O. Resultados semelhantes também foram registrados nas propriedades $\mathrm{B}$ e $\mathrm{D}$. $\mathrm{Na}$ propriedade $\mathrm{C}$, o maior número de frutos por árvore foi verificado no alinhamento de plantio N-S, enquanto na propriedade E essa o foi em NE-SO. Neste último, tal produção, entretanto, não diferiu estatisticamente daquela observada no alinhamento L-O. Ao se analisar a produção em função da face exposta da planta, verifica-se convergência com os resultados obtidos para o alinhamento de plantio, uma vez que as perpendiculares a um alinhamento de plantio de alta produção de frutos apresentaram valores similares. $\mathrm{O}$ mesmo comportamento também foi observado para alinhamentos com baixa produção.

Em relação ao peso médio dos frutos, não foram observados valores estatisticamente diferentes entre si nas propriedades B, C e D. Nas propriedades A e E, os maiores valores foram observados nos alinhamentos de plantio L-O. Em relação à face, não foi possível estabelecer uma relação consistente quanto à sua influência no tamanho dos frutos.

A variável produção incorpora o número de frutos e seu tamanho, sendo, portanto, o melhor indicador de produtividade das plantas. Assim, ao se analisarem os dados das propriedades A e B, constata-se que os alinhamentos de plantio N-S e $\mathrm{L}-\mathrm{O}$ foram os que estatisticamente proporcionaram os maiores valores de produção. Para o caso das propriedades $\mathrm{C}$ e $\mathrm{D}$, essas o foram no alinhamento $\mathrm{N}-\mathrm{S}$. Na propriedade E, por sua vez, a maior produção foi verificada nos alinhamentos de plantios L-O e NE-SO, embora essa não tenha diferido estatisticamente daquela observada em N-S. Quanto à face da planta, não foram observados valores estatisticamente diferentes nas propriedades $\mathrm{D}$ e $\mathrm{E}$, ao passo que, para as demais, as faces $\mathrm{N}$, $\mathrm{S}, \mathrm{L}$ e $\mathrm{O}$ foram as que proporcionaram as maiores produções.

Tomando-se como referência estritamente a média de produção obtida nas propriedades, observa-se que aquelas localizadas ao sul do Estado de São Paulo, como no caso de A e B, foram as 
que apresentaram maiores valores médios, tanto em termos de número de frutos, como quanto ao número de caixas produzidas. Este resultado é parcialmente explicado pela maior sanidade dos pomares localizados ao sul do Estado, e por uma condição de clima representado por temperatura mais favorável ao desenvolvimento dos frutos. De acordo com a literatura, o estresse térmico inclui-se dentre os fatores que influenciam no desenvolvimento, florescimento e frutificação dos citros (Krajewisk \& Rabe, 1995), sendo que, quando há elevação de temperatura, pode haver comprometimento na fixação dos frutos e causar o seu abortamento. Em relação ao alinhamento de plantio, constatou-se que os ângulos $0^{\circ}$ e $90^{\circ}$, representados respectivamente pelos alinhamentos de plantio N-S e L-O, foram os que contribuíram para maior produtividade, provavelmente em função de uma luminosidade mais elevada e mais uniforme.

Em termos de ratio, nas propriedades A e $\mathrm{C}$, esse foi superior no alinhamento de plantio $\mathrm{L}-\mathrm{O}$, enquanto na propriedade $\mathrm{E}$, esse o foi no alinhamento NO-SE. Para as demais propriedades, os valores foram intermediários e não diferiram estatisticamente entre si. Em termos médios, as propriedades citrícolas A e B, localizadas mais ao sul do Estado de São Paulo, e C e D, localizadas mais ao Centro do Estado, apresentaram valores mais baixos de ratio, o que provavelmente pode estar relacionado à menor soma de graus-dia que as plantas foram expostas, já que este parâmetro, segundo Volpe et al. ( 2002), reflete significativamente nos valores dessa variável.

Quanto ao ${ }^{\circ}$ Brix, nas propriedades A, B, $\mathrm{C}$ e $\mathrm{D}$, os maiores valores foram observados nos alinhamentos de plantio L-O. Por outro lado, nas propriedades D e E, não foi verificada uma relação consistente, já que os maiores valores foram observados para os alinhamentos NE-SO, como também o foi em NO-SE, respectivamente. Em termos de localização geográfica da propriedade não foi observado um efeito consistente nos valores de ${ }^{\circ}$ Brix. Por outro lado, em termos de ratio, foi verificado efeito da latitude nos índices dessa variável, cujos índices foram notoriamente mais baixos nos frutos provenientes de pomares localizados mais ao sul do Estado de São Paulo.

TABELA 1 -Municípios, número de pomares avaliados das propriedades citrícolas, coordenadas geográficas, variedades e ano de implantação de pomares citrícolas avaliados quanto à influência do alinhamento de plantio na expressão de sintomas da mancha-preta-dos-frutos cítricos, na produção das plantas e nas características tecnológicas do suco.

\begin{tabular}{lcclc}
\hline \multicolumn{1}{c}{ Municípios } & $\begin{array}{c}\text { Número de talhões } \\
\text { avaliados }\end{array}$ & $\begin{array}{c}\text { Coordenadas } \\
\text { geográficas }\end{array}$ & Variedades & Anos de plantio \\
\hline Itapetininga & 8 & $48^{\circ} 18^{\prime} \mathrm{W} 23^{\circ} 36^{\prime} \mathrm{S}$ & Valência & $1990 / 1991$ \\
Santa C. do Rio Pardo & 4 & $49^{\circ} 21^{\prime} \mathrm{W} 22^{\circ} 50^{\prime} \mathrm{S}$ & Natal & $1997 / 1998$ \\
Rio Claro & 4 & $47^{\circ} 30^{\prime} \mathrm{W} 22^{\circ} 18^{\prime} \mathrm{S}$ & Natal & 1992 \\
Itirapina & 4 & $47^{\circ} 46^{\prime} \mathrm{W} 22^{\circ} 11^{\prime} \mathrm{S}$ & Valência & $1987 / 1988$ \\
Tambaú & 4 & $47^{\circ} 15^{\prime} \mathrm{W} 21^{\circ} 28^{\prime} \mathrm{S}$ & Valência & $1997 / 1998$ \\
\hline
\end{tabular}

TABELA 2- Resultados (valores de F) correspondentes à análise de variância para níveis de severidade de sintomas da mancha-preta-dos-citros, produção e características tecnológicas do suco de laranjas-doces em função do efeito da localização da propriedade (município), face da planta exposta e da localização x faces, obtidos por diferentes alinhamentos de plantios de citros.

\begin{tabular}{lccc}
\hline \multirow{2}{*}{ Variáveis } & \multicolumn{3}{c}{ Valores de F } \\
\cline { 2 - 4 } & Município (A) & Exposição (B) & A x B \\
\hline Sintomas de pinta-preta (sintomas gerais) & $482,08^{* *}$ & $14,99^{* *}$ & $7,09^{* *}$ \\
Sintomas de pinta-preta (falsa-melanose) & $222,05^{* *}$ & $11,35^{* *}$ & $4,49^{* *}$ \\
Número médio de frutos por planta & $75,78^{* *}$ & $15,97^{* *}$ & $12,52^{* *}$ \\
Peso médio dos frutos (g) & $29,61^{* *}$ & $13,32^{* *}$ & $12,66^{* *}$ \\
Número médio de frutos/face & $48,41^{* *}$ & $14,20^{* *}$ & $12,61^{* *}$ \\
Ratio & $145,04^{* *}$ & $24,05^{* *}$ & $18,33^{* *}$ \\
${ }^{\circ}$ Brix & $76,10^{* *}$ & $32,78^{* *}$ & $19,86^{* *}$ \\
\hline tamente significativo (Tukey, $P<0,01)$ & & &
\end{tabular}


TABELA 3 - Influência da face de exposição de plantas de laranjeiras 'Natal' e 'Valência' na expressão de sintomas da mancha-preta-dos-frutos-cítricos, dos tipos mancha-dura e falsa-melanose, na produção das plantas e nas características tecnológicas do suco. (Jaboticabal, 2008).

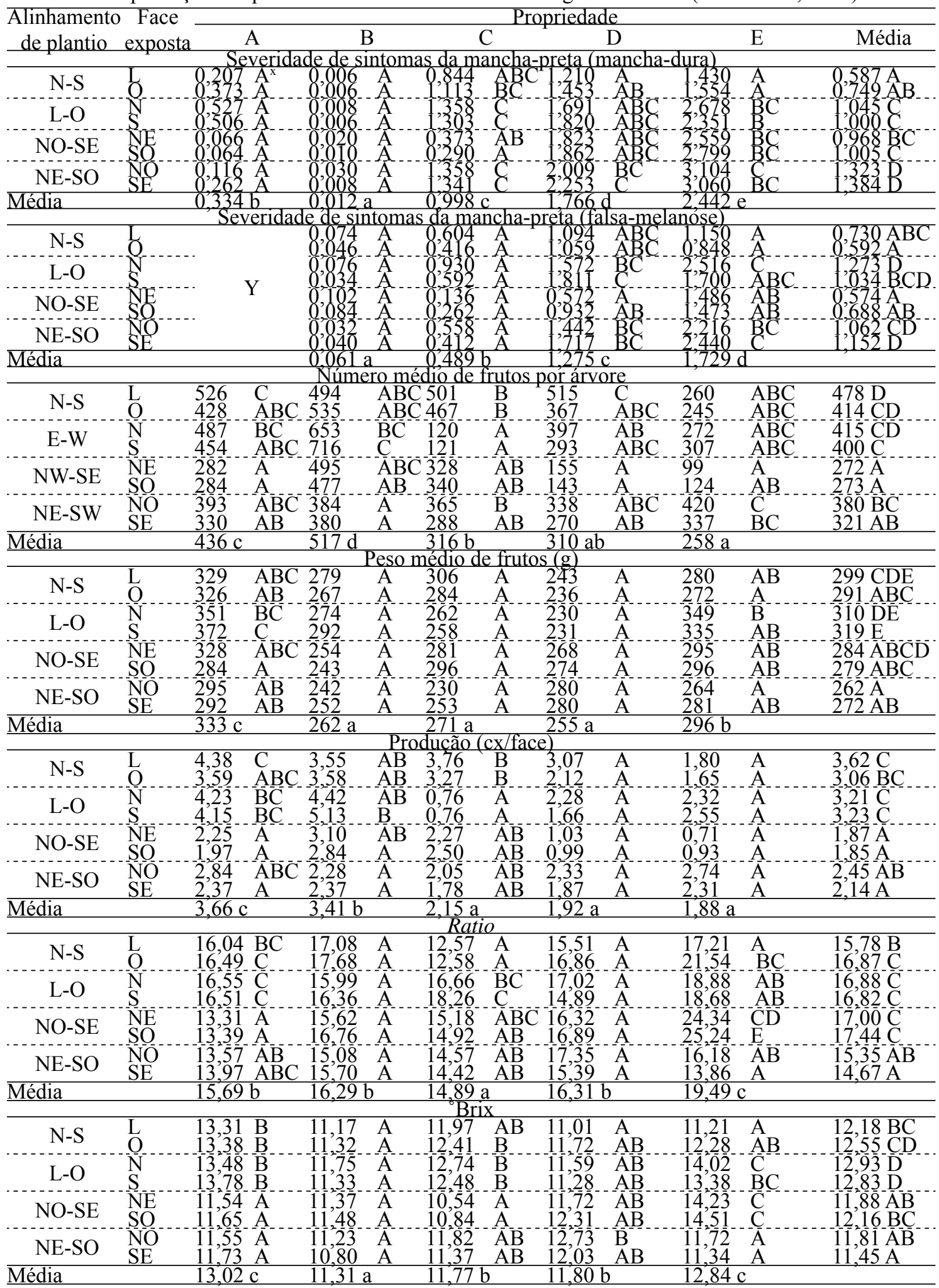

${ }^{x}$ Médias seguidas pela mesma letra, minúscula nas linhas e maiúscula nas colunas, não diferem estatisticamente entre si (Tukey, $\mathrm{P} \geq 0,05)$. ${ }^{\mathrm{y}}$ Avaliação não realizada devido aos baixos níveis de incidência e severidade de sintomas da mancha-preta-dos-citros. 


\section{CONCLUSÃO}

Os menores índices de severidade de sintomas da mancha-preta-dos-citros, tanto em termos de mancha-dura ou falsa-melanose, foram observados nos alinhamentos de plantio N-S e NO$\mathrm{SE}$, enquanto, contrariamente, o foi em L-O e NESO. Tal comportamento aplica-se para o caso das faces das plantas, já que foram observadas relações entre alinhamentos e níveis de severidade de sintomas. Em relação à produção, os alinhamentos de plantio N-S e L-O propiciaram a obtenção de maior número de caixas por planta. Contrariamente, nos alinhamentos de plantio NO-SE e NE-SO, foi onde se constataram os menores valores de produção. Em relação aos índices de ratio e ${ }^{\circ}$ Brix, não foi constatado um padrão definido. Porém, foi constatada relação entre latitude e valor do ratio, sendo consistentemente mais baixo em pomares cítricos localizados mais ao sul do Estado de São Paulo.

\section{REFERÊNCIAS}

ALBRIGO, L.G. Environmental influences on citrus fruit development. In: INTERNATIONAL SEMINAR ON CITRUS PHYSIOLOGY, 2., 1992, Bebedouro. Proceedings... Jaboticabal: Funep, 1993. p.91-102.

AHMEDULLAH, M. Training and trellising grapes for production in washington. Washington: Washington State University, 2006. 12p. (Cooperative Extension Bulletin, EB637).

ARAÚJO, P.S.R. de; MOURÃO FILHO, F.A.A.; SPÓSITO, M.B. Pegamento de frutos de laranjeira 'Pera' em diferentes alturas na copa relacionado aos quadrantes geográficos. Scientia Agrícola, Piracicaba, v.56, n.1, p.157-162, 1999.

BALDASSARI, R.B.; BRANDIMARTE, I.; ANDRADE,A.G. de; SOUZA, D.C.G.; MORETTO, C.; GOES, A. de. Indução da expressão precoce de sintomas de Guignardia citricarpa em frutos de laranjeira 'Pera-Rio'. Revista Brasileira de Fruticultura, Jaboticabal, v.29, n.2, p.269-275, 2007.

BODRICK, H.T.; RABIE, C.J. Light and temperature effects on symptom development and sporulation of Guignardia citricarpa Kiely, on
Citrus sinensis (Linn) Osbeck. Phytophylactica, Pretoria, p.157-164, 1970.

DAVIES, F.S.; ALBRIGO, L.G. Environmental constraints on growth, development, and physiology of citrus. In: Cítrus. Wallingford: CAB International, 1994. p.52-82.

FAGAN, C.; GOES, A. Controle da mancha-preta causada por Guignardia citricarpa e sua influência nas características tecnológicas de frutos de laranja 'Natal'. In: CONGRESSO BRASILEIRO DE FITOPATOLOGIA, 32., 1999, Curitiba. Resumos... Curitiba: Sociedade Brasileira de Fitopatologia, 1999. p.281.

KRAJEWISK, A.J.;RABE, E. Citrus flowering: a critical evaluation. Journal of Horticultural Science, Ashford Kent, v.70, n.3, p.357-374, 1995.

KOTZÉ, J.M. Epidemiology and control of citrus black spot in South Africa. Plant Disease, Saint Paul, v.65, p.945-950, 1981.

MARCHI, R.J. Modelagem de curvas de maturação da laranja 'Pera' (Citrus sinensis L. Osbeck) na região de Bebedouro - SP. 1993. 107f. Dissertação (Mestrado em Agronomia - Área de concentração em Produção Vegetal) - Faculdade de Ciências Agrárias e Veterinárias, Universidade Estadual Paulista, Jaboticabal, 1993.

NOZAKI, M.H. Produção de estruturas reprodutivas e efeito do ambiente nos tipo de sintomas produzidos por Guignardia citricarpa em Citrus spp. 85f. Tese (Mestrado em Agronomia - Área de concentração em Produção Vegetal) Faculdade de Ciências Agrárias e Veterinários, Universidade Estadual Paulista, Jaboticabal, 2007.

SÃO PAULO. Secretaria de Estado de Agricultura, Pecuária e Abastecimento de São Paulo. Previsão da safra agrícola de laranja do Estado de São Paulo, ano agrícola 2007/2008: 1ำ levantamento, maio de 2008. Disponível em: <ftp://ftp.sp.gov. $\mathrm{br} / \mathrm{ftpiea} / \mathrm{mercado} /$ laranja0508.pdf $>$. Acesso em:11 set. 2008 .

SINCLAIR, W.B. The biochemistry and physiology of the lemon and other citrus fruits. 2.ed. Riverside: Agriculture \& Natural Resources, 1984. 946p. 
SOULE, I.; GRIERSON, W. Anatomy and physiology. In: WARDOWSHI, W.F., NAGY, S. (Ed.) Fresh citrus fruits. New York: Florida Science Source, 1986. p.1-22.

SPÓSITO, M.B.; AMORIM, L.; BELASQUE JUNIOR, J.; BASSANEZI, R.B.; AQUINO, R. Elaboração e validação de escala diagramática para avaliação da severidade da mancha- preta em frutos cítricos. Fitopatologia Brasileira, Brasília, v., n. 1, p. 81-85, 2004.
VOLPE，C.A.; SCHÖFFEL，E.R.; BARBOSA, J.C. Influência da soma térmica e da chuva durante o desenvolvimento de laranjas 'Valência' e 'Natal' na relação entre sólidos solúveis e acidez e no índice tecnológico do suco. Revista Brasileira de Fruticultura, Jaboticabal, v.24, n.2, p.436-441, 2002. 